\author{
Jean-Michel Salanskis \\ Université Paris Ouest \\ Nanterre La Défense
}

\title{
WAYS OF INFINITY
}

\begin{abstract}
The paper discusses analogies between the way in which infinity is understood and dealt with in mathematics and in Jewish tradition. It begins with recalling the classical debate about infinity in the field of the foundations of mathematics. Reading an important paper by A. Robinson, we come to the conclusion that mathematicians work "as if" infinite totalities existed. They do so by following the rules of their formalized discourse which, at least if it refers to anything at all, also refers to such totalities. The paper describes how, according to Jewish tradition, infinity is also not theological: instead of thinking that they own some infinite being or relate to it, observant Jews follow Jewish law.

The analogy is then extended to what is called 'epistemological infinity'. The paper shows that both in mathematics and in Judaism, we get some epistemological experience of infinity, as far as both Talmudic knowledge and contemporary mathematical encyclopedia are experienced as inexhaustible sources of new thoughts, structures, ideas, developments.
\end{abstract}

I would like to deal with the topic "Theology in Mathematics?" by examining and comparing how mathematics on the one side and Jewish tradition on the other give room to something which on both sides is called Infinity. I choose Infinity rather than God, because I consider the first term as broader and less prejudicial than the second one. There are a lot of ways of dealing with Infinity, of using it in various senses: it is not always the case that doing so, one takes Infinity as property belonging to some extraordinary divine entity, playing thus the game of theology. And to my eye the most crucial point, concerning such issues, is that neither mathematics nor Jewish tradition force you to take up Infinity in a theological way.

Before going further, I should probably try and give some definition of Infinity. Here, we get into difficulties. The very constitution of the word indicates that Infinity should be defined in terms of the finite: what is infinite is that which is not finite, simply. But then, do we have a satisfactory definition of the finite? One of the surprising discoveries we make studying logic is that it is not possible to define the property, for the class of $x$ satisfying some $A$, of being finite, with some unique first order formula. In 
first order logic with equality, we can define for any integer $n$ the property, for the extension of $A$, to comprise exactly $n$ elements, but we cannot write a formula expressing that the extension of $A$ is finite.

As a matter of fact, there is a foundational dispute about how to define the finite. And connected with it, a dispute about whether we should define infinite in terms of finite - as I just said the structure of the word suggested this - or to define finite in terms of the infinite (as happens in classical set theory).

But I am going to bypass such technical dispute and discussion. I shall assume that there is some intuitive or immediate sense of finite, which precedes at least de jure $20^{\text {th }}$ century mathematics and logic. Finite designates in general what we have access to, what does not stand beyond any possible grasp of ours. And thus Infinite means what stands beyond, what - according to its very definition - cannot be reached or seized.

The basic experience, to which the confrontation of finite and infinite may be referred, for sure, is the constructive experience of natural integers. I have been convinced by Brouwer and ulterior constructive tradition that we clearly share the conception of natural integers as constructions, made up on the basis of emptiness by using and reusing the one and only building rule of 'adding one': we may articulate such recursive definition in various ways, either by stipulating

i) ' 0 ' is a natural integer

ii) if the writing $\mathrm{N}$ is a natural integer, then the writing ' $\mathrm{SN}$ ' is a natural integer;

or by stipulating

i) the empty writing is a natural integer

ii) if $\mathrm{E}$ is a natural integer, then the writing ' $\mathrm{EI}$ ' is a natural integer.

In the first case, our definition coincides with the definition of numerals (names of natural integers) in formal arithmetic: they are specific terms built with the help of tools provided by the formal language.

'Finite', then, may be said of every construction likely to arise according to our recursive definition. Infinite, thus, will be reserved for anything which cannot be constructed. As is well known, the very act of considering the class of all possible constructions sends us beyond the constructability limit: we may construct any construction, but not the achieved whole of all possible constructions. This holds, at least, for each interesting and significant case, where fabrication modes, through their iteration, open up to an unlimited range of constructions.

According to me, no rational attitude may claim to ignore this experience, and the correlated understanding of both notions. We have to un- 
derstand the game of recursive construction, of building items of a class in accordance with some recursive rule, in order to understand and use formal languages: formulas, terms, proofs, cannot be defined but through recursive definition. Further or deeper than that, some understanding of the constructive horizon associated with recursive rules is involved in understanding and using ordinary language, at many levels: we have to understand what an arbitrary chain of characters taken in some alphabet is, what an arbitrary sequence of words is, what an arbitrary sequence of sentences is; we have to be able to make sentences more complex up to any arbitrary level, using some embedding principles like those Chomsky brought to our attention.

Another last remark about this meaning of 'finite': it is not limited by our actual, concrete, natural or physical abilities. We are ready to regard as acceptable finite objects entities of which we are sure they will arise inside the horizon specified by some recursive definition, even if we have to confess we are unable, in our finite lives, to actually carry on their construction: it is enough for us that we a priori envisioned the process of that construction.

\section{Robinson's formulation of Hilbert's position on infinite totalities}

I come to the important point I have in mind about mathematics, i.e. what we could call its 'agnosticism'. It will be at best illustrated by some reflections of Abraham Robinson, a great logician and mathematician whose career was in several ways parallel to that of the Polish hero Alfred Tarski ${ }^{1}$.

As is well known, the conception of the finite I just introduced takes its inspiration from Brouwer, who thought it more or less 'against' the early development of formal set theory he was witnessing. Thus this definition is strongly connected to the Brouwer-Hilbert debate -a debate which was bearing, precisely, on the status of infinite totalities: the infinite sets that formal set theory was introducing, through the axiom of infinity, defining them exactly as standing beyond the constructive finite. Indeed, what the axiom $[\exists x(\emptyset \in x) \wedge(\forall y(y \in x) \rightarrow(y \cup\{y\} \in x))]$ says, is that the alleged set $x$ contains the recursive sequence of sets built on the basis of $\emptyset$ by using repeatedly the building rule [out of $y$, build $y \cup\{y\}$ ], and thus stands beyond each member of that sequence, encompassing all of them.

Brouwer judges that serious mathematics should stay in the realm of the finite (although dealing with its aperture), by accepting only constructions and constructive reasoning. Reacting to his position, Hilbert decided, and 
wished to prove, that it was possible to bypass such limitation, welcoming infinite sets, because we would secure that such a step could never lead us to assert some finite falsity (to prove a false 'inhaltlich' statement, in his words). Hilbert wanted, as he said, to save for the mathematicians the Paradise that Cantor had designed for her (infinite set theory). I would like to quote, now, the way Robinson reformulates Hilbert's choice or decision, in his 1964 paper:

My position concerning the foundations of mathematics is based on the two following main points or principles.

(i) Infinite totalities do not exist in any sense of the word (i.e., either really or ideally). More precisely, any mention, or purported mention, of infinite totalities is, literally, meaningless.

(ii) Nevertheless, we should continue the business of Mathematics «as usual», i.e., we should act as if infinite totalities really existed.

Of the two principles just stated, the first is descriptive while the second is deontic or prescriptive ${ }^{2}$.

Robinson clearly states his position in the context of a debate bearing only about infinite totalities: the debate originating in the Brouwer/Hilbert contest. It is philosophically possible to ask about the existence of a mathematical object in general. This is more or less what Benacerraf does in his famous second paper ${ }^{3}$, which has determined the analytic dispute about mathematics in the recent years: after all, if one wishes mathematical discourse to be true exactly in the same way ordinary discourse is, one would need genuine correspondence for mathematical statements, and thus genuine reference for mathematical names. And finite mathematical objects are no less unsatisfactory in that sense: they also appear as strange or false objects, that no one can perceive or grasp, that have no temporal or spatial location (because they seem to have to be ideal objects).

Infinity, Robinson specifically points out, comes as an infinity of infinite totalities: infinity arises in the context of set theory, and is before all required as an infinity of totalities of finite objects (the infinity of the set of natural numbers, to begin with). So Robinson joins the debate as a mathematician who, on the one side, sees and knows that we have no problem with finite objects and knowledge about them, and on the other side, acknowledges that we need to include all of them in totalities, which cannot but be infinite. The complex infinite hierarchy of infinity results from the straightforward play of the logic of totality (namely, of taking the power set).

First, he formulates his 'atheist' position in a very strong way: infinite totalities do not exist, either really or ideally (which means that he rejects 
them both at the naturalistic and the metaphysical level), and reference to them is meaningless.

But then, he concludes that we should do 'as if' they existed. He does so by clearly distinguishing between descriptive and prescriptive or deontic issues (a language which, if I may observe, sounds surprisingly similar to the one Lyotard used when reacting to Levinas' philosophy ${ }^{4}$ ).

Thus Robinson sees contemporary mathematics as involving infinity, but not in an ontological way. Mathematical discourse deals with infinity, mixes infinite totalities with 'inhaltlich' statements, but without giving credit to them. Infinite totalities are there only for the purpose and glory of finite knowledge. Or, to put it better: talk about the infinite expresses only our commitment to a discourse about finite objects which does not avoid thinking in terms of totalities.

One could add here: how do we practically manage to 'act as if infinite totalities existed', as Robinson puts it? Clearly, the answer is: by obeying the rule of deduction in ZFC, a system where have been kept some names and principles, functioning as implicit traces of infinity. Thus we 'relate' to infinity by following a law of discourse, instead of actually positing such infinity.

I see Jewish tradition as doing something quite similar.

\section{Jewish tradition and theological infinity}

There is a problem about Jewish tradition, which surfaces even in approaches that seem to know nothing about it: a problem I would call epistemological. Usual conceptions take Judaism to be a religion, based on some faith directed towards some omnipotent extraordinary being, supposed to have created the universe. This 'God' is even taken to be the same for each of the three (so called) monotheist faiths (Christianity, Islam, and Judaism): the God of the desert, people say. The alleged God is thought of as having revealed (it-, her-, him-)self to humanity, by delivering holy scriptures making explicit what (it, she, he) asks from us and promises to us. The interconnection of the three faiths becomes clear when one observes that the basic text of Judaism is more or less included in both the basic text of Christianity and the basic text of Islam.

But this account sounds false when one looks at things closely.

Is it so clear that Judaism is about faith? I could recall, here, Hannah Arendt's anecdote (which she herself recounts in the context of an interview): while she was attending a religious course in her youth, she suddenly 
stood up and shouted aggressively these words at her rabbi "I do not believe in God!"; and the rabbi answered "But nobody asks you to!". Indeed, I think that most people know that in Judaism, what counts is that one observes the mitzvot ('commandments'), that one lives in accordance with that extremely complicated set of rules bearing on any possible aspect of life which is called 'Jewish law', and which is formally disclosed in some reference texts, like the Shulchan Aruch: those texts themselves read and extract the law from the huge compilation called Talmud. To say it simply: Judaism asks you to do what has to be done, and not to do what is forbidden, but it does not care so much about what you believe in.

This first remark fits with what everyone may verify by looking at how Jewish people, standing at various distances from dutifully following the Law, live what appears to an external observer as the religious dimension: in a quite prosaic way, not far from materialistic. Accomplishing things that the Law prescribes, being together with others in places devoted to Judaism, does not involve you in some heavenly atmosphere, where you have to show, by your special concentration and special enthusiasm, that you communicate with some entity standing beyond the sensible. The correct and concrete practice of Orthodox Judaism does not bring people into some super-world, does not ravish souls into some superior realm of emotion.

Such observations become understandable when one examines how Judaism works and how Jewish tradition formulates and follows its ideal goal. I am going, in what follows, to expose Jewish tradition as I learned it from Georges Hansel: I cannot do better than recommend his books to someone wishing to grasp the corresponding content with the best possible precision ${ }^{5}$. When one reads outside of any guidelines the Torah - the Old Testament or now the 'First Testament' in Christian terms - one learns that God gave the law to the people of Israel, first on the tablets brought back by Moses, and then in a more detailed version disclosed in specific books of the Torah, the legislative ones. So one is tempted to conclude that one knows what Jewish law is: it cannot but be what God prescribes and which is written in the Torah. Such reading defines the standard theological understanding of Judaism.

Still, this reading simply does not work. When you read the Torah, you learn that when someone hurts one's neighbour, wounds one's neighbour, then the victim will be allowed to exert on the aggressive neighbour exactly the same violence which was inflicted. Isn't that what the text expresses quite clearly with the words 'eye for eye, tooth for tooth'? But Jewish law does not say so. In the Talmud, we find in the Mishnah (written between +100 and +300$)$ that the person who has hurt and wounded has to pay 
money for five damages (damage proper, pain, stoppage of work, cost of cure, and shame). According to Maïmonides there is no memory in Jewish tradition of having ever followed another rule. Thus it seems that Jewish law is not what our naïve reading took for granted.

Indeed, Jewish law is formulated and thought out by doctors of the law: a group of specialized intellectuals who learn and study all their life long, and who have been recognized inside the studying community as the most knowledgeable, the ones able to teach, and to decide. They read, reflect and discuss not only Torah, but also all that has been thought by people of their kind through the centuries, and they attempt at making clearer and more precise in each case 'what the law has in mind'. Deciphering what the law has in mind, thus, is not a straightforward listening directed to the reigning exceptional entity; it is intellectual work, and it enfolds decisions made by the most prominent doctors (the posekim). Various disagreements may appear at times, but after some period of time, sages come to agree ${ }^{6}$ (as it happened in the famous disagreement cases of Hillel and Shamai, or of Maïmonides and Nahmanides).

The development over centuries of Jewish law looks very much like the dogmatic development of a science: rather mathematics than physics, because it is presented as never invalidating anything that has been said. In Gemara, just after the law of monetary compensation for an injury has been formulated, it is justified in reference to the 'eye for an eye, tooth for a tooth': we were wrong in understanding it literally; it meant that some equivalence principle between injury and 'punishment' had to be found (and money makes it possible). Thus the apparent very strong modification brought by the sages is described as a better understanding of a first version: in that way are exposed all additions, all along the epistemological story of Jewish tradition. Explicitly, this development is supposed, also, to work in a sort of democratic way (the law should be chosen like the majority of the sages understand it): such Democracy, however, is at the same time aristocratic, as it concerns only the sages. Georges Hansel formulates things nicely, saying that 'Revelation is decided through the majority'?

This whole picture seems to erase God. There remains, of our 'theos', only the first strata of law, according to the surface story of Torah: a first strata which does not count by itself, because it is meant to be modified and re-exposed in the sages' work and decisions. Tradition is clear about the key Idea that revelation is not the metaphysical relation standing only at the beginning, when God gives the tablets to Moses, but rather what characterizes the whole process: the process of Jewish tradition enriched by sages over centuries, which looks like a scientific process. 
Does this mean that Infinity has been also cancelled? Absolutely not. Jewish tradition undoubtedly conceives of itself as being a witness to Infinity, as working on Infinity, as aiming at Infinity. Tradition rejects a strictly 'organizational' construal of what Tradition is about. Although such a reading is perhaps better than the theological, it is not the right one. Even if Jewish law does nothing else than organizing the collective lives of Jews, it does so in the perspective or under the command of the ethical. And the ethical is understood here in its infinite figure. The easiest way to formulate Jewish Tradition's ethical aim is to take advantage of Levinas' philosophical work. The core of the ethical, according to Levinas, is our unlimited responsibility for the other person, immediately in front of us. We have to help the other person and listen to them, to take them as the miserable incumbent on us or as the master of study speaking to us. And this happens, as we said, in an unlimited way: on one side our obligation is not limited to some contract; on the other side the more we give, the more we owe. Justice, as defined and envisioned by Jewish doctors in the Talmud, attempts to build some social order where our unlimited debt towards our neighbour cannot be forgotten or neglected, where everything recalls to us the ethical maximum: Jewish law wants us to get rid of self-centeredness, and leads us to ethical performance and research. Our relations and our behaviours towards others are therefore examined, interpreted, and ruled in that perspective.

Thus, Jewish law shows its connection to infinity at the level of the radicalism of its rules, of the depth of the consideration for people, their feelings, and their mutual duties that it presupposes and explores. Here, I think one could say that Chassidut, in its strange language, which looks theological, at least from the outside, has formulated such an 'infinite' driven way of life. So, as we see, Jewish tradition adopts the same attitude Robinson was defining: not letting everything depend on the actual ontological position of infinity, but still relating to such infinity or witnessing for it in our concrete way of following certain rules.

But I think we can add another dimension to our comparison, taking into account what I would call 'epistemological infinity'.

\section{Epistemological infinity: mathematics and Jewish tradition}

'Epistemological infinity' refers for me to the way some types of knowledge let us experience that they shelter unlimited intellectual content, that they enfold inexhaustible meaning. Their structure or settings indeed warrant that we are always on the verge of discovering a large amount of un- 
expected applications, or some thrilling generalization, or the definition of some new continent of topics to be studied.

Certainly mathematics gives such feeling. At least people who know something of it may testify to that: it is what makes them 'in love with mathematics'. Mathematics is felt as an amazing kingdom, where always more avenues open up than anticipated, where the diversity of any specific kind of object calls for exploration allowing surprising versions to unveil: a kingdom which is not summarized by some unique map, but that many perspectives totalize and organize in different ways.

For what concerns here the global picture of mathematics, let me give some examples:

1) We have the picture of the hierarchy of ranks, organizing all mathematical objectivity into an infinite cone, measured by the scale of ordinals (a scale illustrating itself some infinity standing beyond any set-infinity). But this picture ignores every quality; it only shows how quantity unfolds.

2) We have the categorical picture: here mathematical objectivity appears as consisting in various 'type of structures' as Bourbaki called them, each of which shows the same internal systematic mode of relations: categories allow higher structural reflection, given by functors, natural transformation and further, always adding levels of mirroring and interactional structures. Categorical construal of mathematical stuff arises as something supplementary to set-theoretical givenness, as a kind of external comment, although, as a French colleague once said in a course for students "One gets easily convinced that categories are for mathematics what clarinet is for New Orleans jazz."

3) We have the recursive constructive picture. Everything that mathematics is about ultimately refers to some constructive strata of objects, building so to say the constructive skeleton of the considered entity. As 'product spaces' in Descriptive Set Theory admit of some recursive presentation $^{8}$. To put it differently; there is no chapter of contemporary mathematics that may not be illustrated by some computational process or display of results. And research, as we know, is likely to take advantage of that by trying to discover 'empirically' what should be conjectured or proved, for example.

4) But we also have the 'imaginative' picture: in mathematics we may introduce new kinds of structures and new kinds of problems, sometimes simply by building bridges between areas of available mathematics. Above all, I am thinking here of the famous bridges that defined contemporary algebraic geometry (associating the topological space $\operatorname{Spec}(R)$ to any commutative ring $R$ ) or topological geometry (associating homotopy or homol- 
ogy groups to any topological space $X$ ). Recently something similar has been made, following the ideas of Gromov, on the basis of groups defined in terms of generators and relations: we may associate to them some graph, and even some metrical space beyond ${ }^{9}$. Thus we may think of mathematical structures as organized in a kind of graph keeping the memory of our imaginative gestures (Thom's drawing was a picture of that kind. ${ }^{10}$ )

Still, there is more: one feels some mysterious magic while exploring mathematical objectivity, or rather, for what I could personally experience, while reading how it has been explored. Objects that we cannot but decide to define, in relation to some field, appear to be exactly the right objects for illuminating and organizing around themselves the whole field. My supervisor Claude Chevalley, for that reason, once said: when we meet two objects that we feel could be the same, and we see an arrow that may be canonically defined from one object towards the other, that arrow is always an isomorphism: we have to prove it because of our deontology, but we know it in advance.

And here is another one: it happens that contemporary language allows us to define a lot of supplementary or encompassing or generalized or structurally connected objects in relation to one unique base object. It is then quite fascinating to discover how the basic object makes sense, and new sense each time, when considered anew from the added perspective. In that way we are given the possibility to always enrich our knowledge of our objects, or of our theorems also, discovering new ways of proving them at some different level. Classical examples would be: seeing the exponential function always from a different perspective (as a power series convergent everywhere on $\mathbf{R}$ or $\mathbf{C}$, as the solution of some very simple differential equation, as a power series defined on some Banach algebra, as function characterized in the general context of some Lie group...); proving the fundamental theorem of algebra in various ways. But those examples are themselves quite elementary.

Put briefly, mathematics seems to shelter an infinite ability to bring new objects and new meaning, to wander through the landscape while at the same time enlarging it and offering new light on it, with additional perspectives being also able to suggest new definitions or conceptions: of algebraic closed fields in Robinson, of groups thanks to quantum group theory ${ }^{11}$, etc.

My next point is quite straightforward. I claim, although with even lesser knowledge (much less in comparison with an already very insufficient amount), that Jewish tradition offers the same kind of richness and feeling of richness. What I have experienced of that (although just as a specta- 
tor of what the master was disclosing), is the case of two "shitot", i.e. two construals of the same law or point of law by two chachamim: when we read the Gemara, we discover, for each case of law, how a principle applies, which may be understood in two ways. Following the shitot, we thus have two perfectly meaningful understandings of why it is decided so in such and such a case. Consequently we can make sense of the same body of decisions in two meaningfully different ways. But my guess is that someone with better knowledge would have much to add: speaking, also, about how various teachings coming from quite different places inside tradition fit together, and seem to answer and help each other (I think here also about the correspondences between Gemara and Midrash or Kabala and Gemara).

I would like to add another layer to the ongoing comparison, reaching back to Chevalley's remark, mentioned four paragraphs before. There is some similar experience in Jewish study: as is well known, we give credit, when working on our sources, to the most ancient voice. The Maharal of Prague makes this point very explicitly in his The Well of the Diaspora ${ }^{12}$. Occidental scholars usually receive such a methodological principle very badly: does it not mean that tradition is always right? Does it not block any possible and open progress? Is it not, to put things more simply, the very opposite of what the scientific attitude has taught us?

But anyone may observe that Talmudic knowledge is nevertheless proliferating. Experience of Jewish study teaches that giving credit is precisely what brings us to put forward some thought that would not have been ours: because we try to make sense, and to make authoritative sense, of what the older masters said, we invent new formulations, new notions. And corresponding procedure gives a feeling of infinity: as far as everything which has been said opens up for unexpected elaboration, avenues for the unlimited emergence of the new seem to be available. So, like in Chevalley's unofficial statement, we win new understanding by postulating it from the onset, more or less.

To sum up, Jewish tradition offers to its scholars an infinite resource for gaining new and profound understanding, quite as mathematics does. Thus both provide some kind of internal purely epistemological experience of infinity. And I think that mathematics and Jewish tradition importantly share such a non-theological 'way of infinity': according to it, the primary figure of infinity is that of unlimited horizons in the theoretical realm, unlimited horizons contributing to the infinitization of meaning.

With that conclusion, I have reached the end of the quick comparative examination I wanted to conduct in this paper. 


\section{N O T E S}

${ }^{1}$ In the context of the present paper we should perhaps remember he was first called Alfred Teitelbaum.

2 Cf. Robinson, A. (1969). Formalism 64. Selected Papers of Abraham Robinson, tome II, Amsterdam, North-Holland, 507.

3 Cf. Benacerraf, P. (1973). Mathematical Truth. The Journal of Philosophy, 70, 661679 .

${ }^{4}$ Cf. Lyotard J.-F. (1980). Logique de Levinas. Textes pour Emmanuel Levinas, Laruelle, F., (éd.), Paris, Jean-Michel Place, 127-150. Republished as a book, Logique de Levinas, Paris, Verdier, 2015. (1983). Le Différend, Paris, Minuit.

${ }^{5}$ Cf. Hansel, G. (1998). Explorations talmudiques, Paris, Odile Jacob. (2008). De la Bible au Talmud, Paris, Odile Jacob.

${ }^{6}$ Cf. Hansel, G. (2008). La controverse talmudique, décadence ou progression. De la Bible au Talmud, Paris, Odile Jacob, 115-132.

7 Cf. Explorations talmudiques, op. cit., 33.

8 Cf. Moschovakis, Y.N. (1980). Descriptive Set Theory, Amsterdam, North-Holland, 116-146.

9 Cf. Starikova, I. (2012). From Practice to New Concepts: Geometric Properties of Groups. Philosophia Scientioe, 16 (1), 129-151.

10 Cf. Salanskis, J.-M. (2008). Philosophie des mathématiques, Paris, Vrin, 193.

11 Cf. Majid, S. (1995). Foundations of Quantum Group Theory, Cambridge, Cambridge University Press, xi-xix.

12 Cf. Loewe, Rabbi (1982). Les Puits de l'exil, trad. fr. E. Gourévitch, Paris, Berg International, 29-35. 